\title{
El amor y el matrimonio entre los iberos
}

\author{
EnCARNACIÓn RuANo Ruiz *
}

Al profesor José M. Blázquez

Resumen

A través de los testimonios iconográficos y literarios tratamos de documentar la relación de la pareja humana en el mundo ibérico

\section{Summary}

Through the iconographic and literary testimonies we try to document the relationship of the human couple in the iberian world.

En todas las sociedades el amor ocupa un lugar destacado como parte indisoluble de la condición humana y en última instancia de la unión carnal, con la procreación como requisito básico primario.

El matrimonio y sus distintas fórmulas es prescindiendo de otras connotaciones, la institución social que regula, ordena y garantiza la unidad de la especie.

Fuentes literarias y documentos artísticos permiten afirmar que en la Grecia y la Roma antiguas el amor y todo lo que tenía relación con él se representó siempre con entera libertad. La pregunta que nos formulamos en esta ocasión es: ¿Cómo fue el amor y el matrimonio en el mundo ibérico?

Contamos para intentar responder a esta pregunta con fuentes arqueológicas y documentales. Pero tengamos en cuenta que la pregunta se contempla en un marco cronológico muy amplio que abarca desde finales del siglo $\mathrm{V}$ a a. de $\mathrm{C}$. hasta el siglo primero de la era. Somos conscientes

* Directora del Boletín de la Asociación Española de Amigos de la Arqueología. 
que no podemos establecer secuencias cronológicas exactas debido a las dificultades de atribuir una fecha precisa tanto a las referencias de los textos escritos como a los testimonios iconográficos.

La dualidad de personajes masculinos y femeninos es muy antigua. Se puede rastrear en la península en el Arte Levantino y esquemático. Precisamente el abate Breuil interpretó ciertas escenas como ceremonias matrimoniales, hipótesis compartida por P. Acosta (Lucas, 1990, 205 ).

Pero, tienen que pasar muchos años para que el modelo iconográfico se vuelva a representar en las obras artfsticas prerromanas. La imagen en relieve del monumento de Pozo Moro realizada hacia el año 500, en los albores de la cultura ibérica, es uno de los primeros documentos sobre esta relación hombre/mujer inmersa sin ninguna duda en una escena erótica como ha enfatizado Almagro-Gorbea $(1982,261)$. (Figura 1).

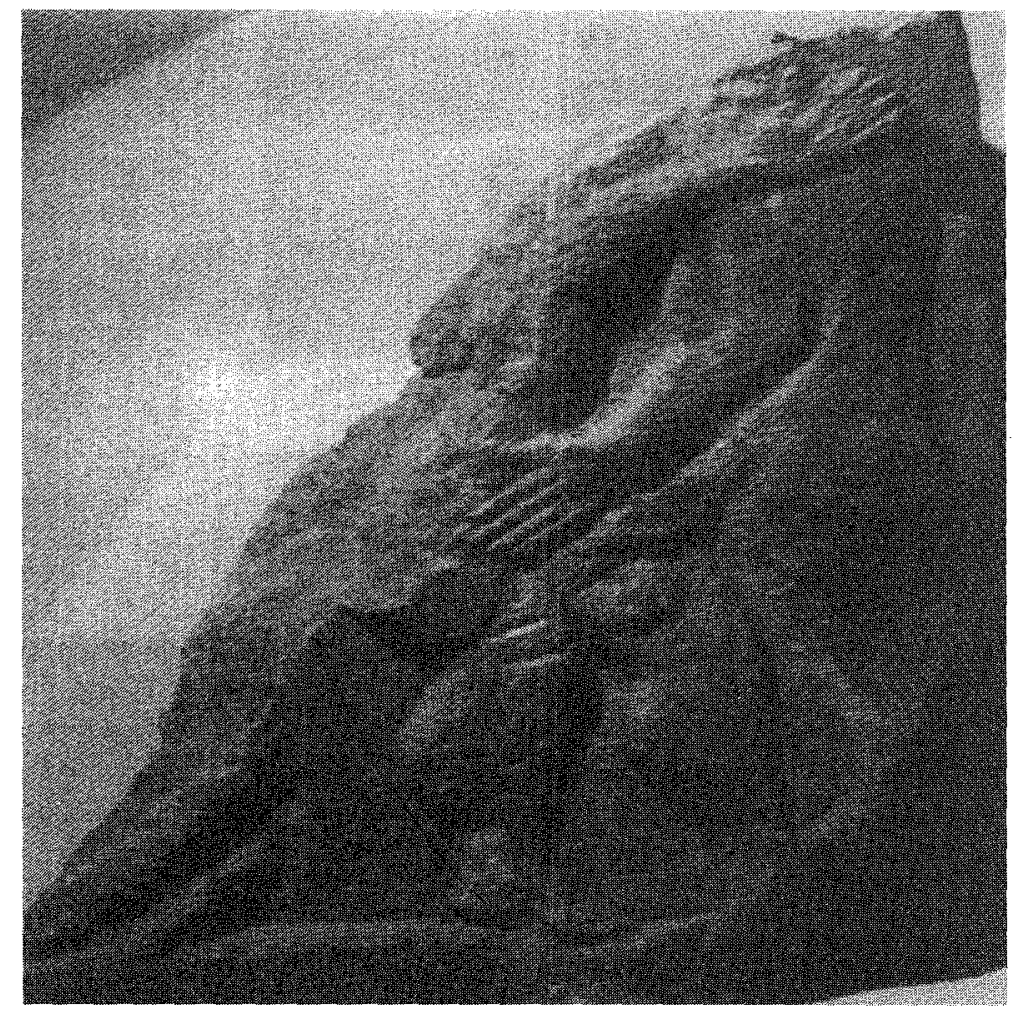

Figura 1. Relieve del monumento funerario de Pozo Moro (Chinchilla, Albacete), según Blanco. 
La escena sexual del monumento funerario de la necrópolis de Albacete representa a un personaje masculino desnudo de pie, que abraza, cogida por el hombro, a una figura, presumiblemente femenina situada frente a él. Esta figura, parece tener la espalda cubierta por una túnica, dirige su mano izquierda al vientre del personaje masculino justo sobre los testículos y el pene que parece introducirse en la mujer.

Ambas figuras no conservan la cabeza y del personaje masculino se ha perdido el tronco. Unas molduras oblícuas situadas detrás del varón tal vez delimitan el escenario de la acción. Con todo, no queremos marginar la observación de Almagro Gorbea, quien plantea la posibilidad que el personaje femenino tuviera aspecto de pez en la parte inferior del cuerpo, si bien este detalle podría ser debido a una rotura en la piedra (Almagro Gorbea, 1978, 266).

La iconografía esculpida en relieve del sillar de Pozo Moro ha sido estudiada tanto por M. Almagro como por J. M. Blázquez, aunque ambos autores no están de acuerdo con la identidad de los actores.

Mientras Blázquez ve en esta escena el pasaje del poema de Gilgamesch (tablilla 1, columna IV) y compara a los personajes con ENKIDU y LA RAMERA o el matrimonio de Inanna-Istar y Damuzi-Tammuz divinidades mesopotámicas. Almagro teniendo en cuenta la situación del relieve en un contexto funerario el acto sexual presupone la generación de la vida a través de la unión de la PAREJA DIVINA (Almagro, 1982, 258).

La escena representada en el relieve que nos ocupa tiene numerosos paralelos en todo el mundo oriental y en el mundo etrusco. Según un estudio recientemente publicado por $\mathrm{J}$. C. Pangas quien escribe y analiza la tableta 104 en texto cuneiforme de la COLECCION ADIVINATORIA «SI UNA CIUDAD ESTA UBICADA SOBRE UN ALTAR", texto formado por más de 107 tabletas, la línea 3 de la citada tableta 104 dice literalmente «si un hombre tiene relaciones sexuales con una mujer estando de pie este comportamiento no es bueno; la enfermedad le está asignada; en el mismo caso ese hombre estará brúscamente inquieto después enfermará (Pangas, 1988, 216).

A pesar de las afirmaciones de este texto, en la vida sexual babilónica la postura de pie aparece en los más antiguos testimonios gráficos, que han sido analizados por J. Cooper en su artículo Heilige Hochzeit como trasmite Pangas.

Por otra parte una escena que recuerda la esculpida en Pozo Moro se pintó en un "enocoe» de imitación corintia, finales del siglo vIl a. de C. (Figura 2). 


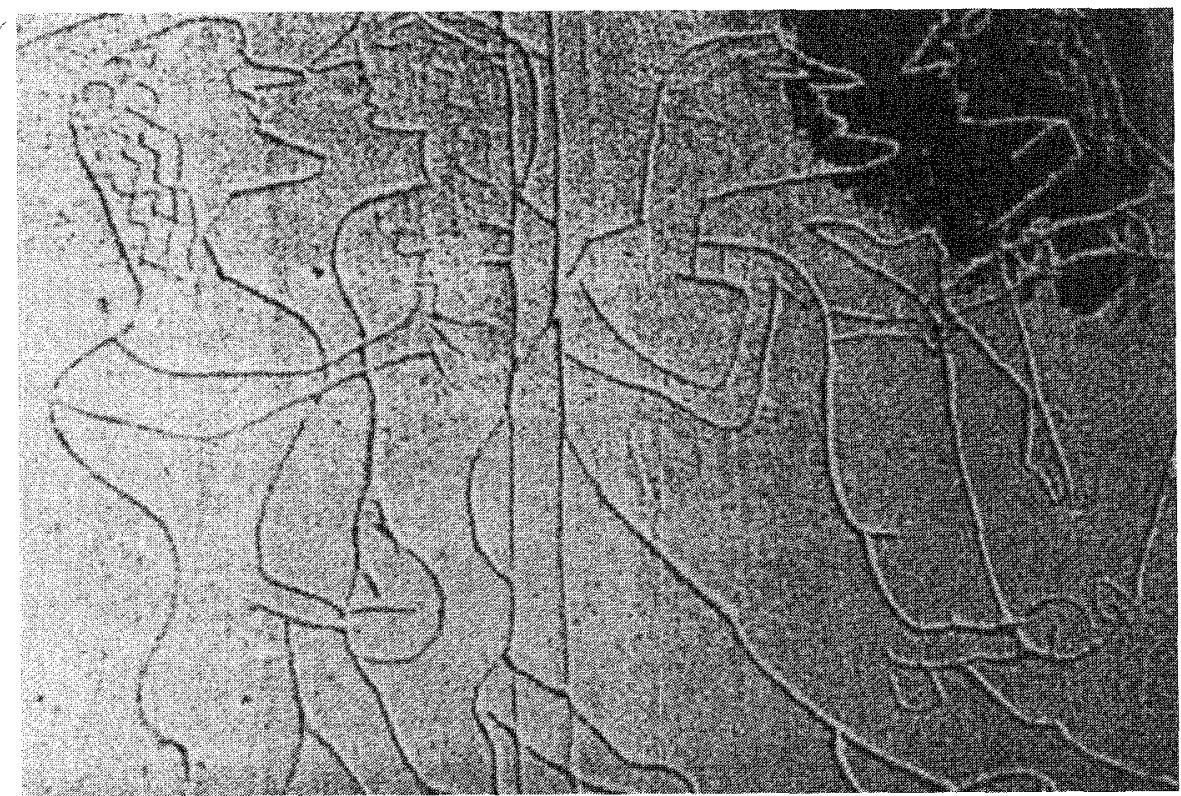

Figura 2. Enocoe de imitación corintia de finales del siglo vil a. de C. (Tagliatella, Etruria), según Blázquez.

Dentro del rico elenco de imágenes ibéricas contamos con otra escena de carácter erótico. Nos estamos refiriendo a la famosa urna de Lobón (Badajoz), procedente de la colección Calzadilla, sobre la que pesan sospechas de falsedad (Montes, 1993). De una manera sumaria describiremos los paneles de los cuatro lados de la urna: 1) Transporte de un recipiente en un carro de cuatro ruedas, con una caja rematada por prótomos de ave. Aparece encima de un friso de cápridos y debajo de una posible parra. 2) Danza ante un ánfora sobre un soporte. Debajo un motivo decorativo complejo. 3) Numerosas líneas entrelazadas y debajo tres espirales 4) Dos jinetes lanceros que preceden a una escena erótica aislada por un recuadro en una esquina; encima se situaron el sol y un ramiforme. La escena que nos interesa representa el acoplamiento de dos personajes de pie y con el cuerpo un poco doblado, situados de tal forma que sugieren la práctica del coito anal entre una pareja de distinto sexo (Figura 3). La figura femenina de la urna de Lobón tiene ciertas dificultades para admitir este sexo pues la imagen presenta una cabeza demasiado voluminosa y está deteriorada. 


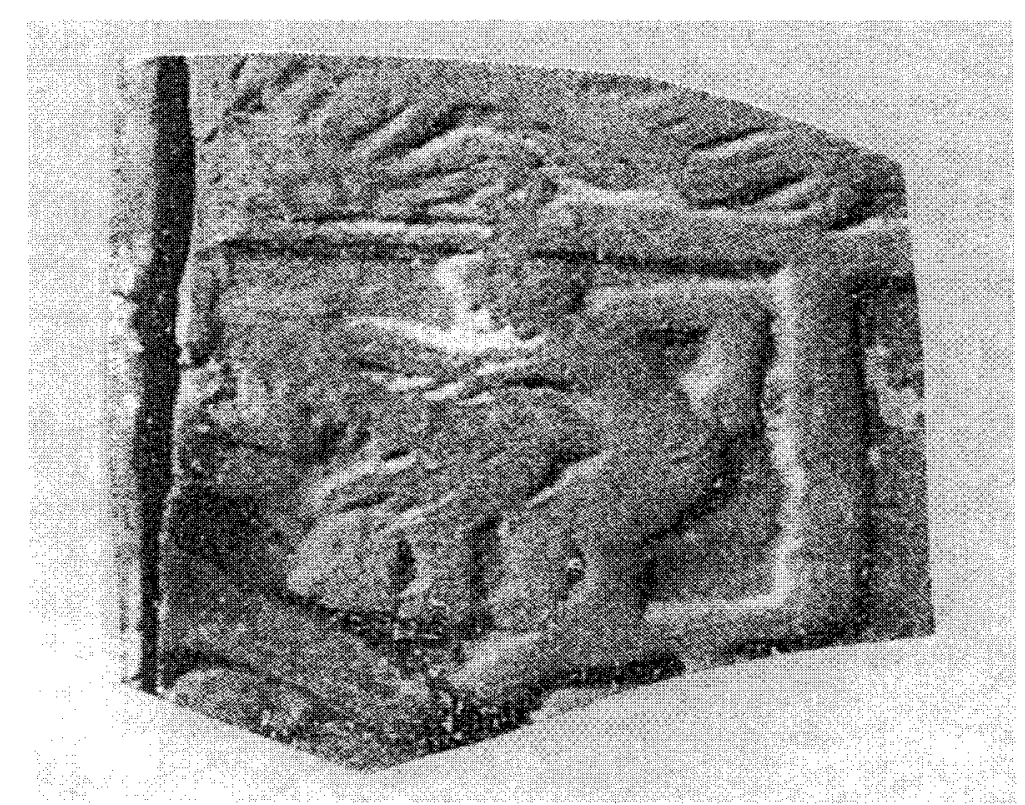

Figura 3. Relieve esculpido en una urna procedente de Lobón (Badajoz), según Kukhan.

La representación podria compararse a las decoraciones pictóricas de la Tumba etrusca de los Toros donde se representó una escena similar. La tumba etrusca con decoración pintada ha sido fechada hacia la segunda mitad del siglo VI (Sprenger; Bartolini, 1972, 315) (Figura 4).

El coito anal con damas está frecuentemente representado en vasos griegos. Varias escenas eróticas donde se repite el esquema de Lobón se pintaron en un ánfora ática griega de terracota. El vaso proviene de una tumba de Tarros y se conserva en el museo de Sassari. Fue pintado entre el año 570-500 por el pintor Timiades (Pesce, 1962, 119).

Por otra parte abundan los vasos de figuras negras, en donde se pintó el coito anal tanto entre sátiros, ménades como entre hombres y mujeres, lo que indica que era frecuente en Grecia (Blázquez, 1987, 51-54).

No obstante las dos representaciones ibéricas con carácter erótico son singulares y excepcionales en la iconografía ibérica, dándose la coincidencia de que se destinaran ambas a contextos funerarios. En el caso de Pozo Moro se sugiere que la acción erótica tiene lugar en un espacio sagrado donde se acoplan las figuras (una columna definiría este espacio). 


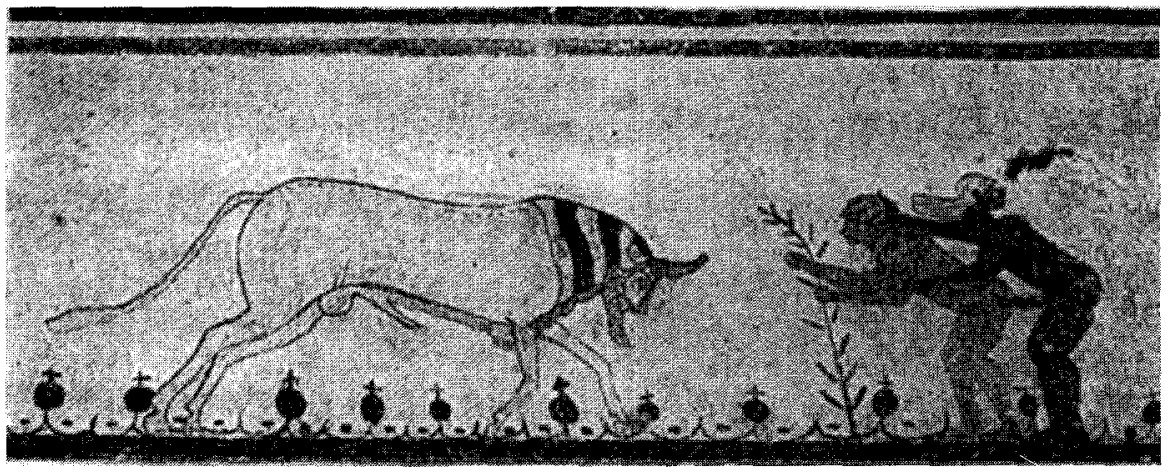

Figura 4. Decoración de la tumba de los Toros (Tarquinia), según Sprenger y Bartolini.

Tambien en la cista de Lobón el espacio que ocupa la escena se ha delimitado como queriendo imitar una estancia. A tenor de estas coincidencias cabe plantear una doble hipótesis. Por una parte la hierogamia o unión sagrada con participación de los dioses, por otra la presunción que las escenas tengan algo que ver con la prostitución sagrada. Esta última manifestación religiosa está vinculada a la divinidad Afrodita/Astarté y parece ser que el culto, a pesar de tener rasgos específicos, tuvo sin embargo tambien un carácter común, propio de una religiosidad internacional, supraétnica, que vinculaba estrechamente la actividad comercial con el ámbito de esta divinidad femenina, que atendía la compleja y delicada relación religiosa y sexual de quienes deben salir fuera de su hogar con el comercio (Olmos, 1991, 104).

Son muchos los santuarios dedicados a la PROSTITUCIÓN SAGRADA valga un ejemplo que lo corrobora, como el situado en Gravisca bien estudiado por Torelli. Estuvo en funcionamiento desde el año 600 a. de C. al 250 y en su primera fase existió un NAISKOS dedicado a Afrodita (Torelli, 1977, 398-458).

El material votivo de la tercera y cuarta fase de este santuario ha sido estudiado por A. Comella. Curiosamente se depositaron variados exvotos anatómicos principalmente úteros. Existen exvotos escultóricos entre ellos parejas en actitud estante y sedente. Estas ofrendas proceden del edificio dedicado a Afrodita y a Hera-Uni (Comella, 1978, 55 y ss.) (Figura 5). En Cádiz conocemos la existencia de un culto a la Venus Marina o Astarté en un promontorio que penetraba hacia el mar en la pequeña isla de Erytheia (Olmos, 1991, 105). 


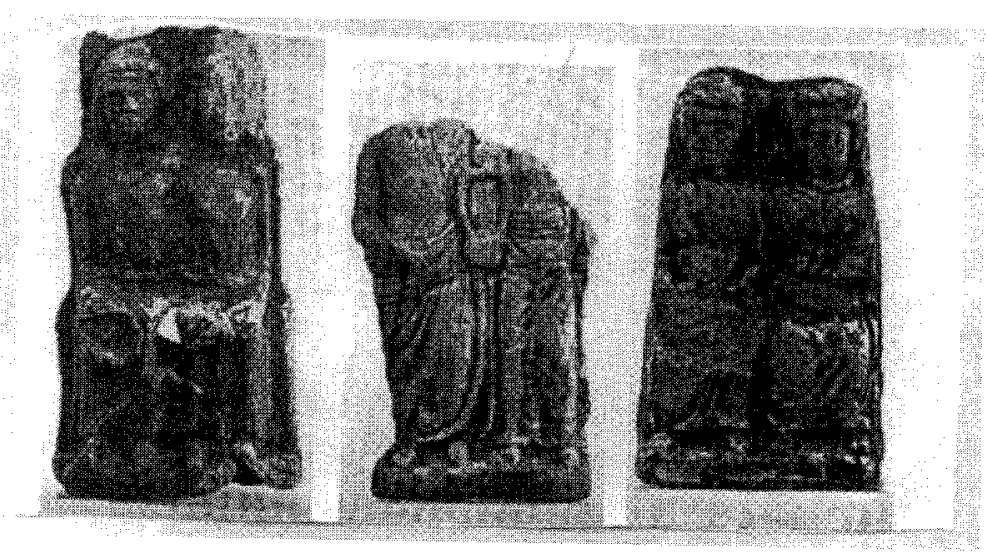

Figura 5. Esculturas procedentes del santuario de Gravissa, según Comella.

En cualquier caso, la intensidad amorosa de las representaciones de Pozo Moro y Lobón y el hecho de aparecer en un contexto funerario definido, descartan la relación con la vida sexual y religiosa vinculada con los comerciantes y el culto a Afrodita y por tanto la hipótesis parece encaminada al simbolismo de una unión sagrada.

También queremos llamar la atención sobre la pareja representada en el bellísimo relieve de La Albufereta. La lectura una vez más evoca la pareja ibérica y el dolor ante la ausencia del ser querido (Figura 6).

De juego erótico podríamos calificar un relieve procedente de Osuna (Sevilla). Un hombre y una mujer están situados de perfil sólo se aprecia la parte superior del tronco y se unen físicamente mediante un beso. Los personajes están vestidos y se adornan con collares, un torques el varón y un hilo de cuentas la dama. (Figura 7).

La escena recuerda la actitud de galanteo reflejada en un vaso procedente de Creta, fechado en el segundo cuarto del siglo vil donde Zeus y Hera se acarician en un acto de preludio amoroso (Buschor, 1940, fig. 56) (Figura 8).

La unión simbólica de la pareja aparece en el mundo ibérico en tres representaciones escultóricas realizadas en bulto redondo, una en actitud estante y dos en posición sedente. La pareja de pie con actitud oferente se depositó como exvoto en el Santuario de El Cerro de los Santos (Montealegre del Castillo, Albacete) (Figura 9). A este Santuario perteneció la ofrenda escultórica de dos personajes al parecer sedentes hoy desaparecidos. (Engel; París, 1906, 437). 


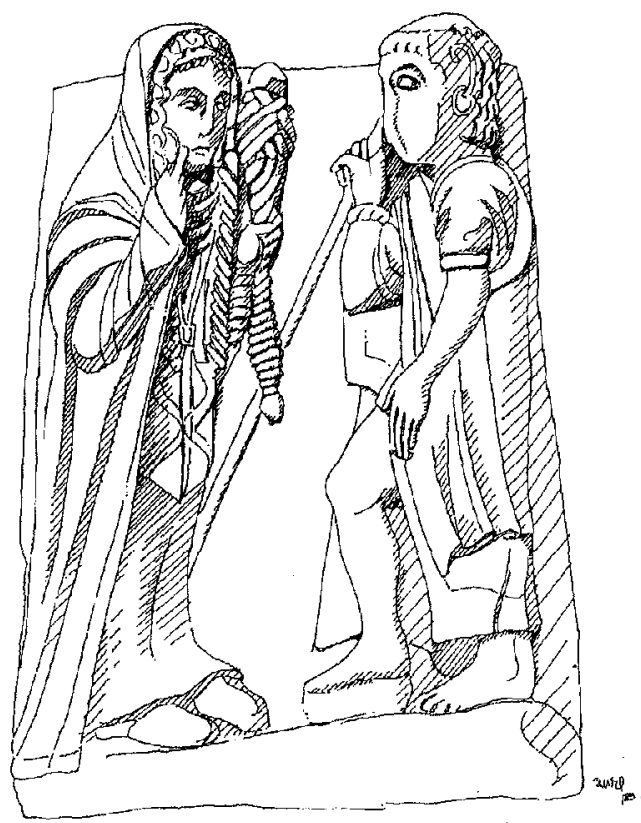

Figura 6. Relieve procedente de la necrópolis de La Albufereta (Alicante), según S. González.

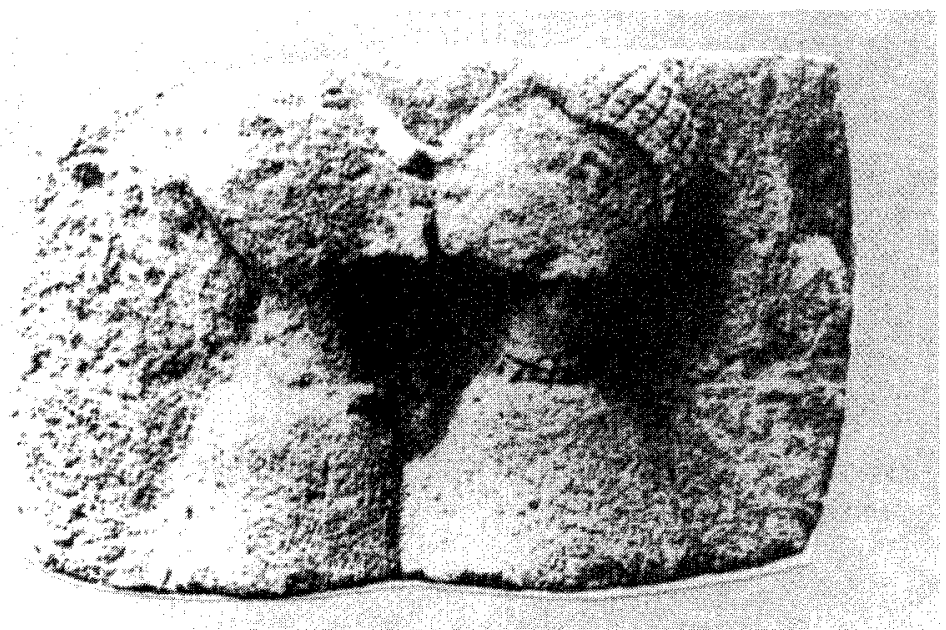

Figura 7. Sillar con figuras en relieve procedente de Osuna (Sevilla). Museo Arqueológico Nacional (Madrid). 


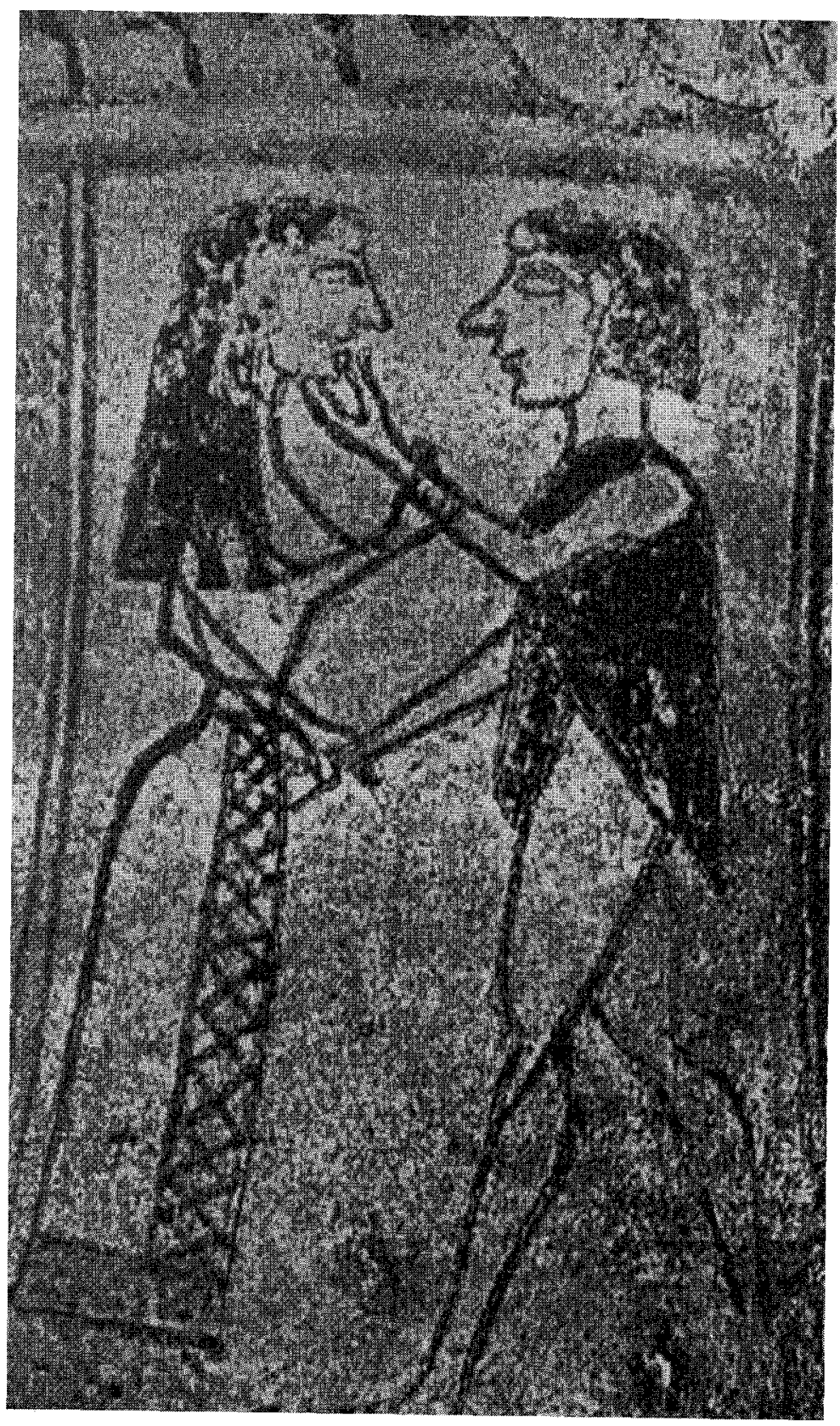

Figura 8. Zeus y Hera pintados en un vaso procedente de Creta, segün Bushor. 


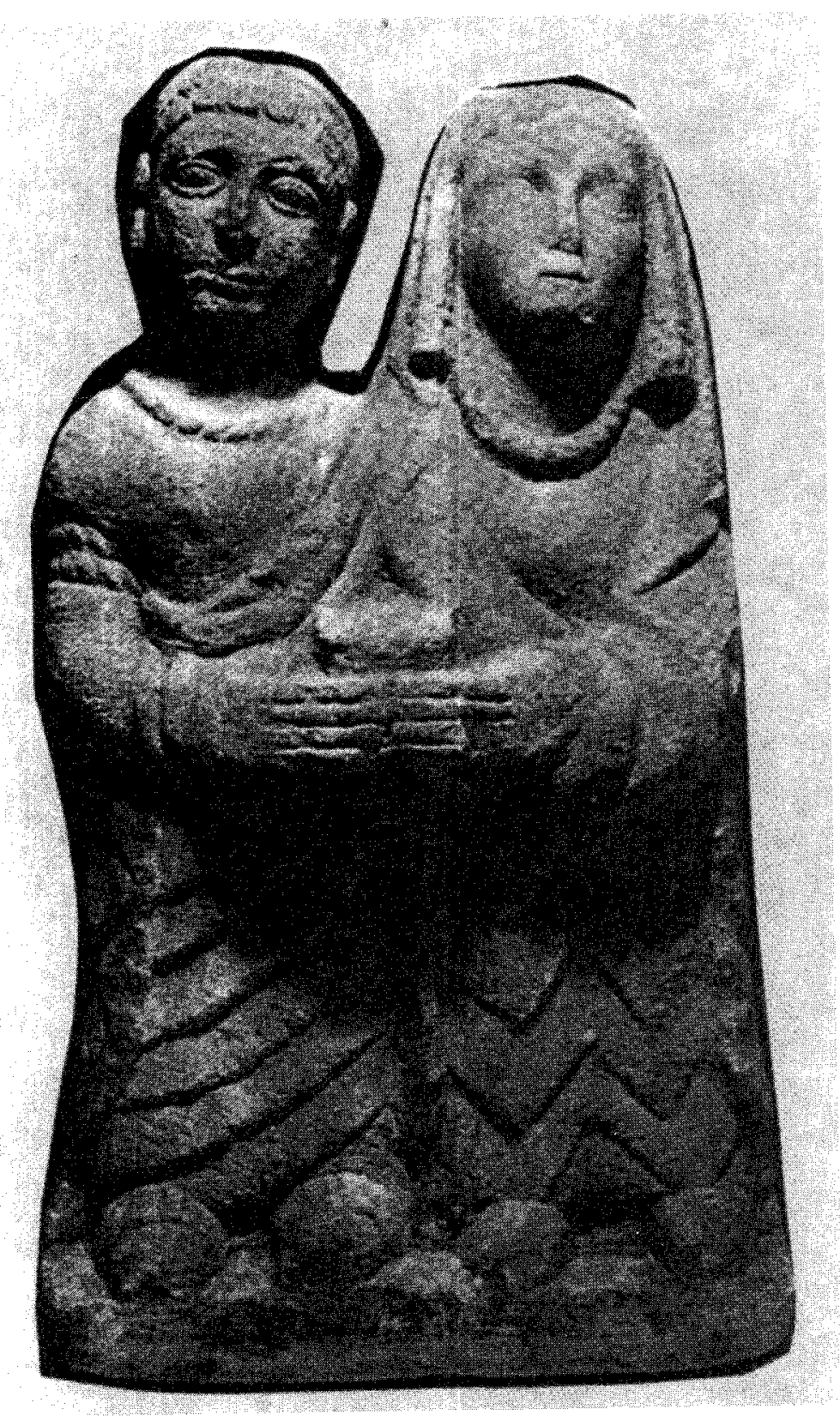

Figura 9. Pareja de oferentes. Escultura procedente del santuario del Cerro de los Santos (Montealegre del Castillo, Albacete). 
Otra pareja sentada procede de la Torre de los Herberos (Dos Hermanas, Sevilla) (Figura 10).

Los dos conjuntos escultóricos tienen un gesto en común la unión de sus manos.

Debemos señalar la importancia que tienen las manos en la antigüedad y la unión de las manos derecha e izquierda en individuos de distinto sexo. Esta circunstancia es puesta de manifiesto por $F$. Marco quien transmite las investigaciones realizadas por el sociólogo $\mathrm{R}$. Herz quien atribuye a la mano derecha su asociación a la pujanza sagrada, a la vida, a la verdad y a la belleza, a lo uránico, al sexo masculino y la mano izquierda la asocia a los contrarios. Según Plinio (NH 7, 77) VIRES DEXTRA MAIORES SUNT.

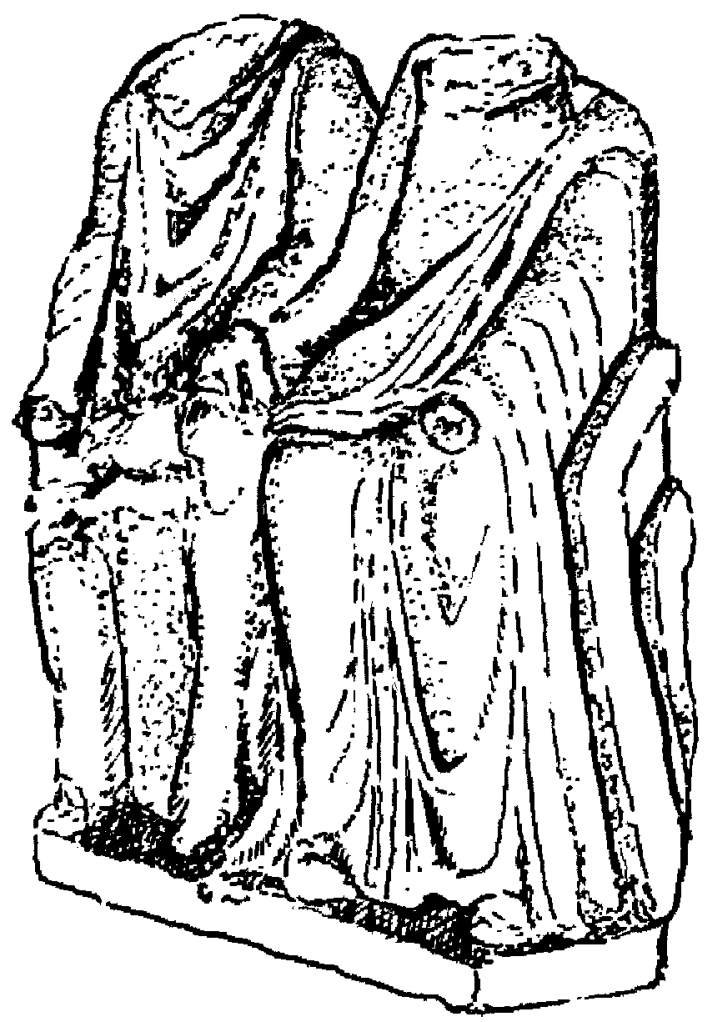

Figura 10. Personajes sentados en un banco. Cortijo de Tixe (Dos Hermanas, Sevilla). 
La derecha es la mano benéfica, es el espacio de la fuerza y la «virtus», el testimonio de la "fides" y de la paz. La mano izquierda se relaciona con lo femenino y la derecha con lo masculino (Marco, 1986, 90).

Las dos parejas ibéricas poseen, una comunicación afectiva que sugiere el vínculo del matrimonio. Conviene recordar aquí nuevamente los exvotos escultóricos de parejas ofrecidos al Santuario de Gravisca dedicado a Afrodita y Hera-Uni. No debemos marginar el conjunto esculpido hallado en Albelda de Llitera (Huesca). Dos personajes de distinto sexo se han representado exentos en esculturas de bulto redondo y aunque no representan una unión física si existió voluntad de figurar como una pareja. Los personajes están sedentes y desnudos, no conservan la cabeza y la figura masculina, tiene esculpido un gran falo, que no permite dudar de su género (Figura 11) por opción, atribuimos personalidad femenina a la escultura complementaria.

La lectura iconográfica del personaje masculino recuerda las representaciones de los exvotos de Torreparedones (Córdoba) y los exvotos hallados en el supuesto Santuario de Torre de Benzalá (Torredonjimeno, Jaén) En ambos casos los exvotos parecen estar relacionados con cultos de fecundidad.

La figura femenina desnuda no tiene paralelos formales sobre todo por las escasas representaciones en el arte ibérico de figuras femeninas sedentes
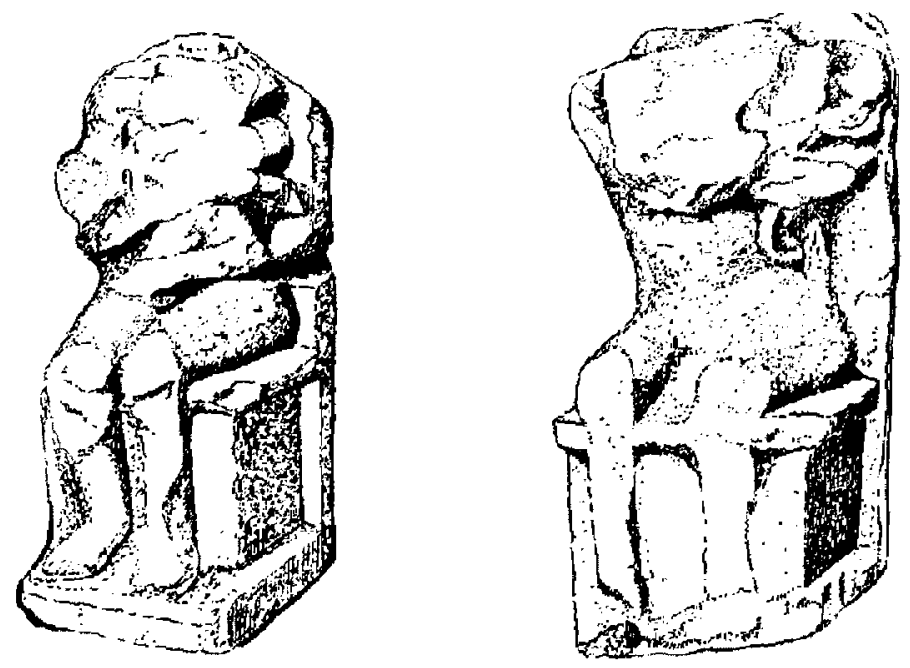

Figura 11. Esculturas procedentes de Albelda de Litera (Huesca). 
privadas de ropa, a excepción de la dama de Villaricos (Almería) (Ruano, 1987, vol. III).

Para F. Marco el conjunto escultórico de Albelda representa una pareja de dioses. Básicamente el autor se apoya en la desnudez de las esculturas y en su actitud entronizada y sugiere que estos elementos plásticos expresan una idea de heroización asumida por los pobladores indígenas sobre las bases de influencias helénicas y romanas de la zona. (Marco, 1990, 332-335).

A estos testimonios iconográficos hay que añadir los arqueológicos. La existencia de enterramientos dobles en algunas necrópolis, parece confirmar la unión de la pareja. Este hecho fue puesto de manifiesto por la doctora Lucas y ahora ha sido objeto de un artículo escrito por el doctor Cuadrado excavador de la necrópolis de El Cigarralejo. Las tumbas 200 y 277 fechadas en el siglo IV son tumbas principescas. En la tumba 200 la cremación de cadáveres masculino y femenino fue simultánea y los restos se enterraron juntos. El enterramiento 277 contenía un ajuar digno de un personaje de élite sin duda masculino y en el mismo enterramiento se introdujo una mujer con un lujoso acompañamiento de pertenencias que la igualaban en importancia al prestigioso varón. La inclusión de una vasija con un grafito escrito, traducido como LA SIERVA DE MILK nombre de procedencia cartaginesa justifica la propuesta de Cuadrado que considera a los enterrados como un matrimonio.

Según el prestigioso investigador en otra tumba de menor categoría, se había apartado la mitad del empedrado tumular y en la mitad descubierta se introdujeron los restos de otro acompañante (Cuadrado, 19891990, 111-112).

Las hipótesis planteadas respecto al matrimonio de los íberos perfilan una sociedad monógama.

Tras este breve repaso podemos preguntarnos. ¿Cómo eran las ceremonias del matrimonio en época lbérica?

Existe un texto de Estrabón (III, 3, 7) que nos puede ayudar a conocer el matrimonio indígena .... "Así entre los cantabroi (Lusitanos, gallegos, astures y cántabros) se casan al modo griego". Recordemos brevemente como eran los rituales de boda griegos. Las fiestas se prolongaban durante tres días. Se iniciaban con la PROAULIA, baño preparatorio pre nupcial en la fuente. - El segundo día tenía lugar la ANAKALIPTERIA acto en que se presentaba oficialmente la novia-. ANAKALIPSIS significa descubrimiento, desvelación y alude al rito de descubrir el rostro para mostrarlo al novio. El tercer día se desarrollaba la EPAULIA. A primeras horas 
de la mañana una procesión con los amigos y familiares del novio acercaban al hogar nupcial los regalos de la boda (Olmos, 1986, 137). En esta comitiva iban los novios que subidos en un carruaje abrían el desfile, como muestra una escena pintada en una cajita de cosméticos de figuras rojas fechada en el siglo $v$ a. de $C$.

¿Qué relación podemos encontrar entre ésta ceremonia griega y algunas imágenes y textos ibéricos?

En Santa Catalina del Monte (La Alberca, Murcia), se encontró un vaso con la decoración bastante deteriorada, donde una dama sedente de la que sólo resta la cabeza y parte del respaldo de lo que se supone un trono (Ruano, 1991, 40), completa la escena una columna y un personaje delante de ella del que sólo se ve la parte superior del cuerpo, pero que permite adivinar que está de pie (Figura 12).

El pintor situó la escena dentro de un edificio sugerido por una columna (Jorge, 1969, 200). La dama sedente y el oferente situado en pie, tienen la cabeza cubierta por sendos casquetes cónicos. La figura femenina está cubierta con un velo, que trata de alzar, para descubrir su rostro.

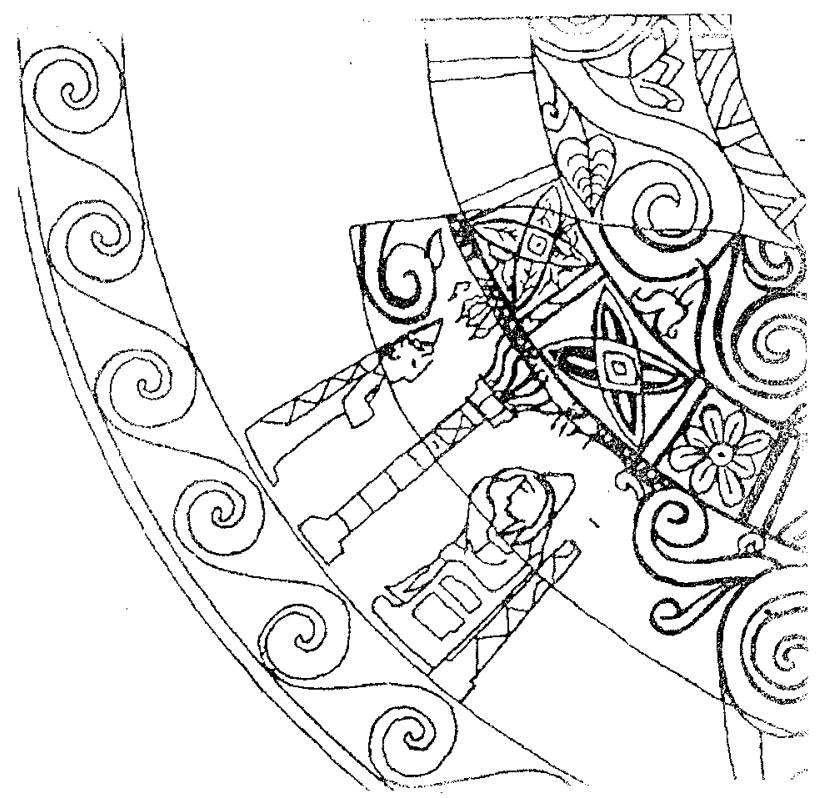

Figura 12. Intento de reconstrucción del vaso ibérico de Santa Catalina del Monte (La Alberca, Murcia). 
La pintura del recipiente de Santa Catalina es un acto de desvelación o ANAKALIPSIS en esta ocasión de una diosa ante un mortal, el trono y el templo así lo sugieren. La referencia iconográfica supone que la imagen era familiar para quien la contemplaba y que este acto podría ser trasladado del campo de lo sagrado al propiamente humano.

No obstante las representaciones de damas veladas con el rostro tapado no son frecuentes en el mundo ibérico, sólo conocemos una escultura depositada en el Santuario del Cerro de los Santos (Ruano, 1987, vol. III, Figura AB-359). La condición del Santuario albacetense como centro geopolítico donde se harian pactos y alianzas entre miembros de distintas comunidades (Ruano, 1990) aboga por interpretar el exvoto, como el de una novia. (Figura 13).

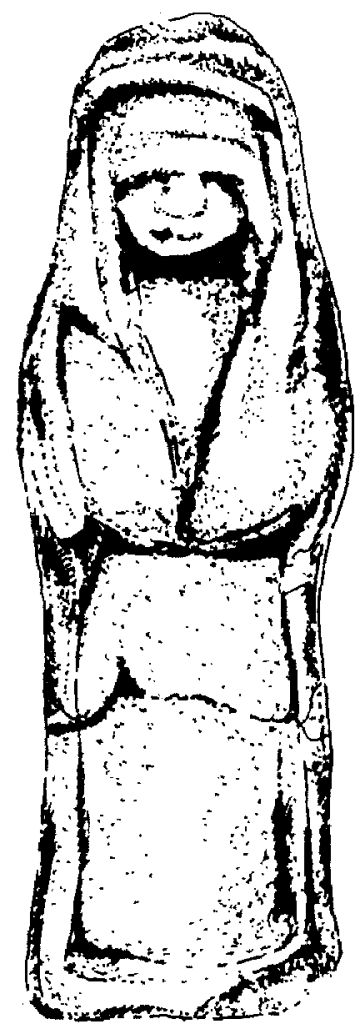

Figura 13. Exvoto encontrado en el santuario del Cerro de los Santos (Montealegre del Castillo, Albacete), según Ruano. 
El ceremonial griego del matrimonio, LA PARTIDA AL NUEVO HOGAR de la pareja se podía poner en relación, con la escena representada en un fragmento de vasija procedente de Liria. Una pareja ataviada con lujosas galas monta un enjaezado caballo. Al conjunto le precede una esfinge (Figura 14).

Para mejor entendimiento de esta escena convendría recordar aquí el texto de Diodoro (XXXIII, 7,1$)$ referido a las bodas de Viriato, «habiéndose expuesto con motivo de sus bodas gran cantidad de copas de plata y de oro y vestidos de muchas clases y colores, Viriato, apoyándose en su

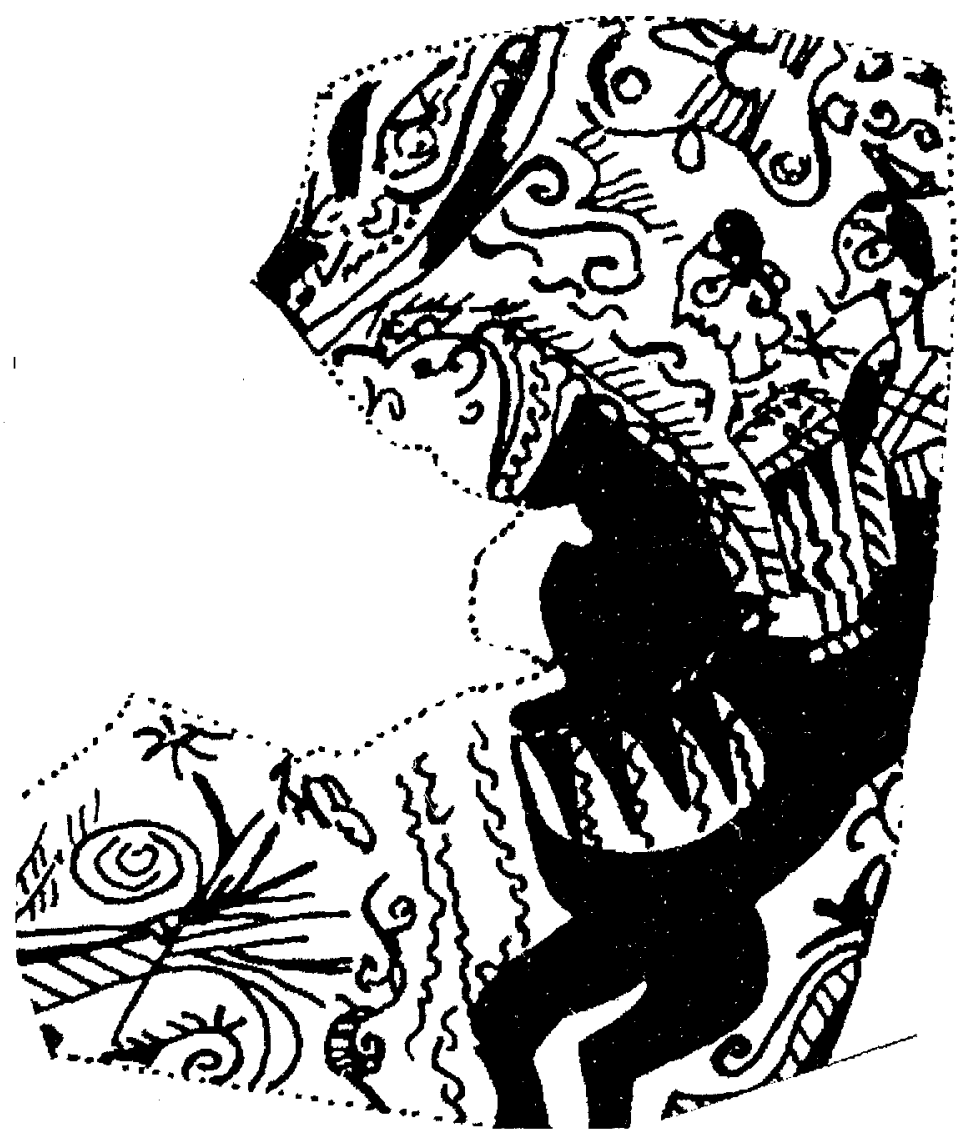

Figura 14. Fragmento de pintura vascular procedente de San Miguel de Liria (Valencia), según Maestro Zaldivar. 
lanza, miró con desdén todas estas riquezas sin asombrarse ni maravillarse de ellas antes bien manifestando desprecio... Por lo demás Viriato a pesar de que fue rogado insistentemente a ello, ni se lavó ni tomó asiento en la mesa, que estaba llena de todo tipo de manjares. Únicamente tomó panes y carne y la distribuyó entre los que le acompañaban, limitándose por su parte a llevarse a la boca un poco de comida. Luego mandó que le llevaran a la novia, sacrificó a los dioses al modo que suelen hacer los iberos, SENTO A LA NOVIA EN SU CABALLO Y SE PARTIO AL PUNTO HACIA LA SIERRA EN BUSCA DE SU ESCONDIDA MORADA (Rabanal, $1970,68)$.

Si la imagen de Liria testimonia la ceremonia de la partida al nuevo hogar, no cabe duda que el acto debía ser habitual en los enlaces matrimoniales. Como RITOS DE BODA con carácter específico del pueblo íbero podrían interpretarse varios documentos representados en pintura vascular y en relieve procedentes del Levante y Sur peninsular. Imágenes de hombres y mujeres cogidos de las manos ejecutan danzas que como ya propusiera sugestivamente la doctora Lucas formarían parte de la unión de la pareja. Este sería el caso de algunos de los bailes denominados por $\mathrm{R}$. Castelo como DANZAS DE MANOS ENTRELAZADAS (Castelo, 1990), concretamente las representadas en el CALATOS de Liria, donde destaca del grupo, una mujer que da la mano a un varón y que lleva en la indumentaria un distintivo de mayor categoría que las demás damas. Esta pareja sugiere la UNION NUPCIAL donde la música formaría parte de estas ceremonias, en las que se exalta la alegría por la vida (Figura 15).

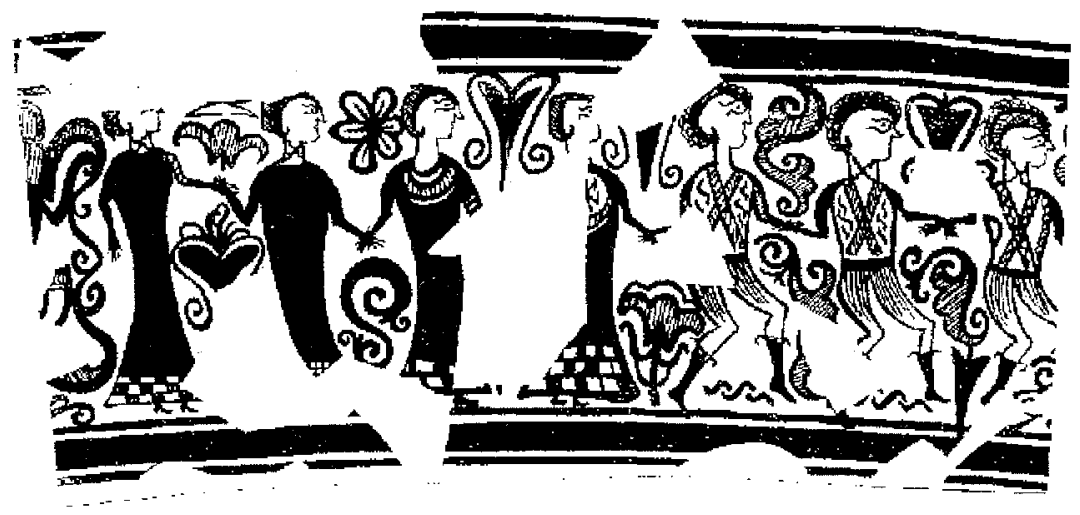

Figura 15. Fragmento de pintura procedente de San Miguel de Liria (Valencia), según Maestro Zaldivar. 
Un segundo vaso encontrado en la misma estancia del poblado valenciano, al parecer un templo, presenta una escena en el friso superior donde tres mujeres cogidas de la mano evolucionan. La última da la mano a un guerrero.

Un tercer vaso de Liria muestra a cuatro mujeres cogidas de las manos y una quinta que ofrece una paloma a un hombre situado enfrente de ella. Este personaje lleva un puñal de hoja cordiforme y empuñadura biglobular y con el brazo izquierdo sujeta una lanza de punta triangular (Maestro, $1989,139)$. Dando la espalda a este guerrero, hay otro hombre, que parece llevar una diadema y que extiende sus brazos a una figura borrosa que pudiera ser itifálica.

El baile en esta ocasión parece que forma parte de un ritual en que interviene una pareja que está perpetuando un contrato, como propuso Lucas (1986, 362) (Figura 16).

En relación con la pareja, resulta sugerente la decoración pictórica de un fragmento procedente de El Palomar de Olite. Dos figuras una masculina y otra femenina se representaron de frente. La dama lleva una túnica, en este caso muy sencilla y parece enlazarse al hombre que viste un traje

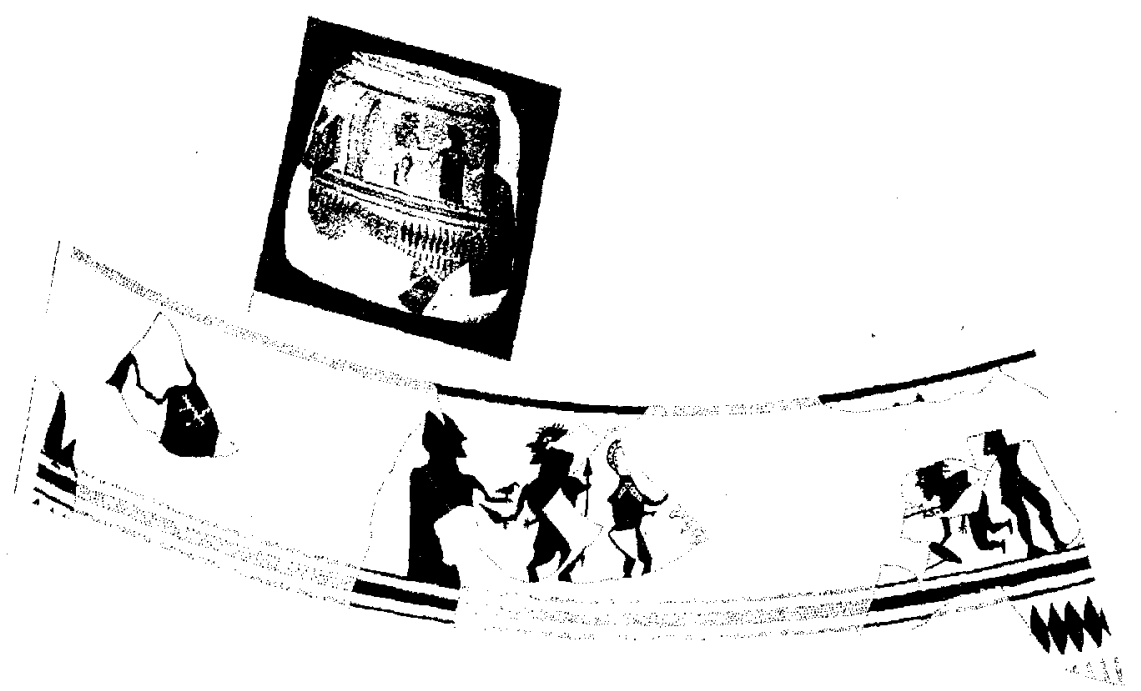

Figura 16. Fragmento de pintura vascular procedente de San Miguel de Liria (Valencia), según Maestro Zaldívar. 
con escote redondo y mangas cortas ajustado al cuello, tirantes y cinturón completan el atuendo. La forma en que se han interpretado las cejas, nariz y ojos sugiere la presencia de una careta (Maestro, 1989, 74). La escena tiene tres elementos decorativos que podrían interpretarse como un timaterio, una palma y una columna (Figura 17).

El fragmento cerámico del Monastil refleja una pareja unida mediante la fusión de las manos (Maestro, 1989, 257). Además el pez que se pintó cerca de los personajes hace alusión a la fecundidad (Lucas, $1981,251-275)$ reforzando más este aparente vínculo matrimonial. (Figura 18).

La misma lectura que las danzas figuradas en las cerámicas de Liria antes descritas daríamos a las figuras representadas en la plaquita de piedra procedente de Fuerte del Rey (Jaén). En esta ocasión la pareja esculpida en mayor tamaño que las otras sugiere una CELEBRACION NUP$\mathrm{ClAL}$, donde los novios están acompañados por familiares y amigos que les acompañan en la danza con las manos ENTRELAZADAS (Figura 19).

Debemos señalar que todas estas danzas conservan viejos arquetipos de bailes fálicos de tiempos remotos, en los que los ritos nupciales son

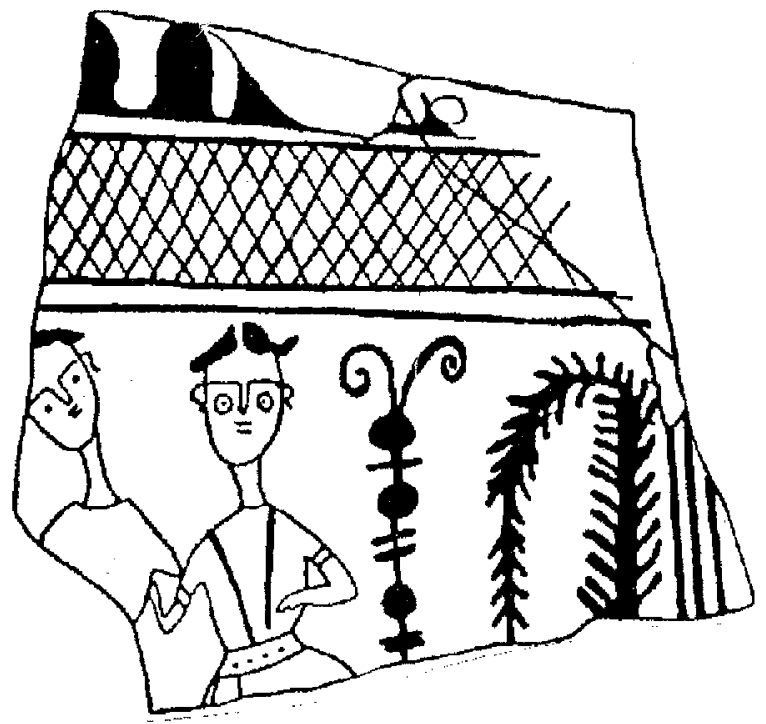

Figura 17. Pareja representada en una cerámica procedente de El Palomar de Olite (Teruel), según Maestro Zaldívar. 


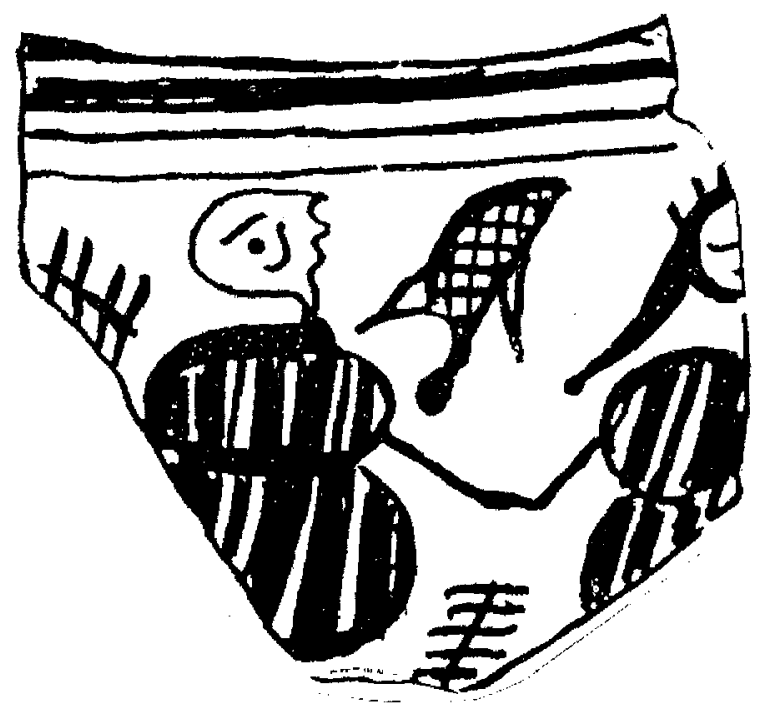

Figura 18. Pareja pintada sobre un vaso de El Monastil (Elda, Alicante), según Maestro Zaldívar.

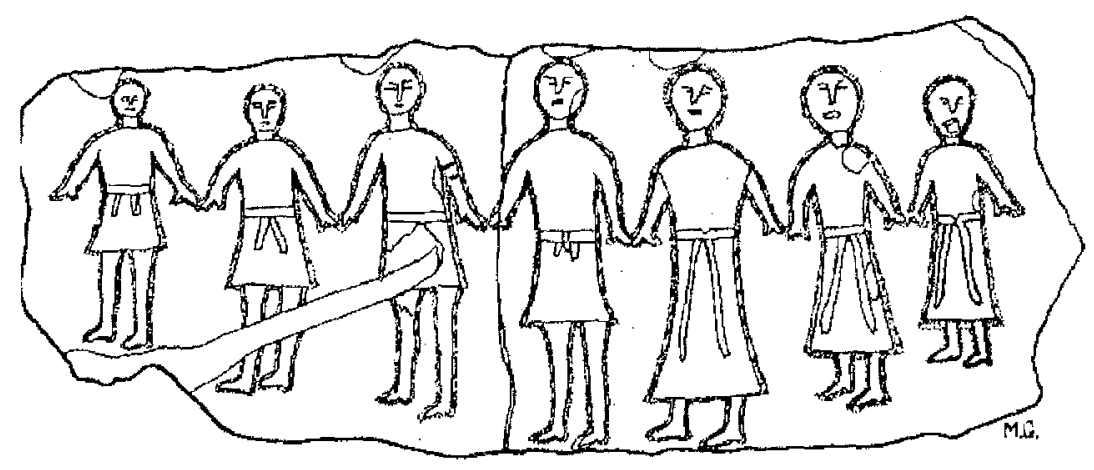

Figura 19. Plaquita de piedra procedente de Fuerte del Rey (Jaén), según Blázquez. 
impulsores de la unión de seres supremos capaces de renovar cíclicamente el acto primordial de la creación.

Los documentos epigráficos y las fuentes aportan interesantes datos para conocer cómo los matrimonios mixtos se utilizaron para suavizar la política. La mujer contribuyó a esta política matrimonial. Según Estrabón (III, 4,18 ). «Son las mujeres las que heredan, y las que se preocupan de casar a los hermanos".

Sugerente es la opinión de Teresa Chapa y Pereira cuando proponen la sucesión a través de la mujer. Este hecho lo atribuyen entre otros argumentos al considerar las joyas como símbolo de su estatus femenino y a la descompensación entre el adorno de las representaciones escultóricas y los materiales hallados en las tumbas (Chapa; Pereira, 1991, 23-25). Los autores consideran el oro como objeto prioritario de la transmisión por herencia del poder y de la propiedad.

La importancia de la mujer en el mundo ibérico llevó como hemos apuntado a fortalecer vínculos diplomáticos. Como se desprende de la lectura del grafito encontrado en la tumba doble de El Cigarralejo permite suponer que en una tumba, estaban enterrados un íbero y la sierva de MILK nombre de procedencia cartaginesa (Hoz, 1984, 11-14).

La creciente asimilación púnica se manifiesta como vemos en la onomástica llamada ibera. Tambien Himilce (I-mil-ke, en fenicio) se casó con Anibal, testimonio conocido a través de Tito Livio XXIV, 41, "Cástulo ciudad de España muy fuerte y famosa y tan adicta a los cartagineses que la esposa de Aníbal era de allí, pasó sin embargo a los romanos» (Contreras, 1975, 24).

Son los procedimientos diplomáticos los que permiten a Asdrúbal el fortalecer y extender el poderío cartaginés en la Península. Diodoro dice «...que Asdrúbal vió que la mansedumbre era más práctica que la violencia y que prefirió la paz a la guerra. Recibe la sumisión de las ciudades del reyezuelo Orisson, contrae matrimonio con la hija de un rey ibero y es proclamado general de los iberos» (Diodoro, XXV, 12).

De todos es conocida la boda de Viriato con la hija de Astolpas como vimos en párrafos anteriores.

A tenor de las fuentes, un hecho parece cierto: La sociedad ibérica o una parte de ella fue exógama y aceptó de buen grado el matrimonio entre etnias diferentes.

La unión matrimonial y la despedida de la pareja del relieve de La Albufereta corrobora una vez más la monogamia institucional de la sociedad ibérica. 


\section{CONCLUSIONES}

La lectura de los documentos artísticos, apreciaciones de índole arqueológica y las fuentes permiten establecer las siguientes conclusiones:

La existencia de la pareja es una realidad en el mundo ibérico. Puede manifestarse bien como acto de unión con la divinidad, como un acto de unión entre seres mortales. Con todo la representación del acto sexual no tuvo apenas relevancia iconográfica.

El matrimonio fue monógamo.

Existieron rituales matrimoniales comparables en cierta manera a los griegos dotados sin duda de un matiz local.

Las ceremonias podrían constar de varias partes, entre las que se incluiría la DESVELACION y la CONDUCCION al nuevo hogar y que se complementaba con danzas y música.

La sociedad fue exógama y a tal respecto se constata las uniones para realizar PACTOS y MATRIMONIOS de carácter POLÍTICO donde las mujeres se utilizaron para consolidar las relaciones diplomáticas y que tuvieron por objetivo las alianzas matrimoniales con las princesas iberas.

\section{BIBLIOGRAFIA}

Almagro GorbeA, M. 1978. "Los relieves mitologizantes de Pozo Moro", TP 35, 25 ss., Madrid. Almagro-Gorbea, M. 1982. «Pozo Moro y el influjo fenicio en el período orientalizante de la Península lbérica», RSF 10, 231-272.

BLÁzQUEZ, J. M.; GELABERT, M. G. 1987. "Arte y erotismo en la Grecia Antigua», Revista de Arqueología N. ${ }^{\circ} 77,47-58$, Madrid.

Blázquez, J. M.; Gelabert, M. P. 1990. «Arte y erotismo en la Roma Antigua», Revista de Arqueología N. ${ }^{\circ} 83,40-53$. Madrid.

BLÁZZQUEZ, J. M.; GELABERT, M.P. 1992. "Amor, sexo, e inmortalidad en el mundo antiguo», Revista de Arqueología N. ${ }^{\circ} 137,38$ ss., Madrid.

BUSHOR, E. 1966. Griechische Vasen, Munchen.

CABrera, P. Griñó. B. 1987. «La dama de Baza. ¿Una diosa tejedora en el allende?. Estudios de lconografía II, Coloquios sobre el Puteal de la Moncloa, MAN Catálogos y Monografías 10, 193-203, Madrid.

CASTELO, R. 1990 "Aproximación a la danza en la Antigüedad hispana. Manos entrelazadas «Espacio Tiempo y Forma, Serie II, Historia Antigua, T. 3, 19-42, Madrid.

COMELLA, A. M. 1978. II materiale votivo tardio di Gravisca, Roma.

Contreras de la Paz, R. 1975. Cástulo en las fuentes. Cástulo I, Acta Arqueológica Hispana, 139, Madrid.

CUADRADO, E. 1989-1990. "La cremación funeraria de los iberos» Anales de Prehistoria y Arqueología N. ${ }^{\circ} 6,111-113$, Murcia.

ChapA, T; Pereira, J. «El oro como elemento de prestigio social en época ibérica», AEA 64, 2365, Madrid.

EnGEL, A; PARis, P. 1906. "Une fortesse iberique á Osuna (Fouilles 1903)», Nouvelles Archives des missions scientifiques, 13,4 .

Figueras PACHECo, F. 1946. «El grupo escultórico de Alicante, AEA 19, 309-333. 
Hoz, J. DE, 1984. «Los grafitos de El Cigarralejo y los signos mercantiles griegos en Hispania, Boletín de la Asociación Española de Amigos de la Arqueología 19, 11-14.

Jorge ARAgONESES, M. 1967. "La badila ritual ibérica de La Luz" Anales de la Universidad de Murcia, XXVI, Murcia.

Jorge Aragoneses, M. 1969. «El vaso ibérico de Santa Catalina del Monte, Murcia», AEA N. ${ }^{\circ}$ 42, 201-204, Madrid.

KukAHN, E. 1966. «Una caja funeraria ibérica con representación en relieve, IX CAN, Zaragoza, 293-295.

LAFUENTE VIDAL, J. 1935, “Un altorrelieve de la necrópolis cartaginesa de la Albufereta», Las Ciencias N. ${ }^{\circ} 4,76$ ss.

LuCAS Pellicer, MR. 1970. "Santuarios y dioses en la Baja Época Ibérica», Actas de la Baja Época de la Cultura lbérica, 233 ss.

LucAs Pellicer, M. R. 1986, «La mujer símbolo de fecundidad en la España Prerromana», Actas de las quintas jornadas de investigación interdisciplinar. - La mujer en el mundo antiguo UAM, 345 ss., Madrid.

MAESTRO Zaldivar, ME. 1989. Cerámica ibérica decorada con figuras humanas, Zaragoza.

MANGAS, J. 1970. "El papel de la diplomacia romana en la conquista de la Península ibérica», Hispania, 30. N. ${ }^{\circ} 116,485-551$.

MARCO SIMÓN, F. 1986. "Topografía cualitativa en la izquierda y en la derecha como elemento de determinación simbólica en la magia romana", Memoria de Historia Antigua VII, 81-91.

MARCo Simón, F. 1990. "Las esculturas de Albelda de Litera (Huesca) y la heroización en el mundo ibérico del Nordeste Peninsular», Zephyrus, XLIII, 329-338.

Montes Bernárdez, R. 1993. Falsificaciones arqueológicas en España. Madrid.

Olmos, R. 1982. "Anotaciones sobre la representación de la mujer en Grecia", Actas de las quintas jornadas de investigación interdisciplinar. La mujer en el mundo antiguo. UAM, 123166, Madrid.

OLmOS, R. 1991. «Puellae Gaditanae ¿Heteras de Astarté?», AEA, 64, 99-109.

OLmos, R. 1991. «El surgimiento de la imagen en la sociedad ibérica La sociedad ibérica a través de la imágen, Madrid.

PANGAS, J. C. 1988. "Aspectos de la sexualidad en la Antigua Mesopotamia", Aula Orientalis VI, 216 ss.

PARIS, P. 1903-1904. Essaí sur l'Art et l'Industrie de l'Espagne primitive, París.

PESCE, G. 1961. Sardegna punica, Cagliari.

PlÁ BALlester, E. 1952, "Notas sobre las cerámicas de San Miguel de Liria unos fragmentos de interés», CAN, 405-418.

RABANAL, M. 1970. España antigua en las fuentes griegas, Madrid.

Ruano Ruiz, E. 1987. La escultura humana de piedra en el mundo ibérica Madrid.

Ruano Ruiz, E. 1991. El mueble ibérico, Madrid.

Santos Yanguas, M. 1980. Textos para la Historia Antigua de la Península Ibérica, Oviedo.

SPRENGER, M.: BARTOLINI. "Die etrusker kunst und Greschiche, Munchen. Studia Archaeologica, 14.

TORELll, 1977-1977 "Il Santuario greco di Gravisca, Lazio Arcaico, e mondo greco», La Parola del Passato, Fas. CLXXVII, 398-458. 